\title{
Nasal carriage rate of methicillin resistant Staphylococcus aureus among Dessie Referral Hospital Health Care Workers; Dessie, Northeast Ethiopia
}

Agumas Shibabaw ${ }^{1,2^{*}}$, Tamrat Abebe $^{2}$ and Adane Mihret ${ }^{2,3}$

\begin{abstract}
Background: Staphylococcus aureus is a common cause of community and hospital acquired infections. One of the important sources of staphylococci for nosocomial infection is nasal carriage among hospital personnel. Emergence of drug resistant strains especially methicillin resistant Staphylococcus aureus is a serious problem in hospital environments. The aim of this study was to determine the nasal carriage rate of methicillin resistant Staphylococcus aureus among Dessie Referral Hospital healthcare-workers in Ethiopia.
\end{abstract}

Methods: A cross sectional study was conducted on a total of 118 healthcare workers. Nasal swabs were collected and cultured on Mannitol Salt Agar. Slide coagulase test was performed. An oxacillin susceptibility test was carried out on Muller Hinton agar using modified Kirby-Bauer disc diffusion method.

Results: Of the 118 healthcare workers, 34 (28.8\%) carried S. aureus of which 15 were methicillin resistant. Therefore, $12.7 \%$ of all HCWs were identified as MRSA carriers. The rate of methicillin resistance among all S. aureus isolates was $44.1 \%$ (15/34). MRSA carriage was particularly high among nurses (21.2\%). The highest rate of MRSA carriers (57.1\%) were workers of surgical wards.

Conclusions: The high rate of nasal MRSA carriage among healthcare workers found in this study indicates the need for adjusted infection control measures to prevent MRSA transmission in our healthcare setting.

Keywords: MRSA, Healthcare workers, Nasal carriage, S. aureus

\section{Introduction}

Staphylococcus aureus is a major cause of community and healthcare infections, and methicillin-resistant $S$. aureus (MRSA) is currently the most commonly identified antibiotic-resistant pathogen in many parts of the world. Treatment of infection caused by S. aureus has become more problematic since the occurrence of methicillin resistance, as MRSA strains are resistant to all $\beta$-lactam antibiotics thereby significantly limiting the treatment options. Concerning Africa, several countries reported

\footnotetext{
* Correspondence: agumas2000@gmail.com

'Department of Microbiology and Immunology, Faculty of Medicine, Wollo

University, Dessie, Ethiopia

${ }^{2}$ Department of Microbiology, Immunology and Parasitology, School of

Medicine, Addis Ababa University, Addis Ababa, Ethiopia
}

Full list of author information is available at the end of the article
MRSA as a problem [1-4], but there is still a lack of good epidemiologic data.

With a few exceptions, the incidence of nosocomial infection caused by MRSA continues to increase worldwide [5]. Infections caused by MRSA strains are associated with longer hospital stay, prolonged antibiotic administration, and higher cost than infections caused by methicillin-susceptible Staphylococcus aureus strains. Next to colonized patients and contaminated environmental surfaces, colonized healthcare workers (HCWs) can act as a reservoir for the spread of MRSA to patients and other HCWs [6].

Identification of patients and healthcare workers (in outbreak settings) colonized with MRSA, combined with hand hygiene and other precautions have been shown to be effective in reducing the transmission and controlling
C Biomed Central

(c) 2013 Shibabaw et al.; licensee BioMed Central Ltd. This is an Open Access article distributed under the terms of the Creative Commons Attribution License (http://creativecommons.org/licenses/by/2.0), which permits unrestricted use, distribution, and reproduction in any medium, provided the original work is properly cited. 
the spread of MRSA. In the current study we conducted a cross sectional study to determine the nasal carriage rate of MRSA among HCWs of Dessie Referral Hospital in Ethiopia.

\section{Materials and methods}

The study was carried out from November 2010 to March 2011 in Dessie Regional Health Research laboratory. A cross sectional study was conducted on a total of 118 Dessie referral hospital HCWs. The study participants were selected proportionally according to the number of HCWs in each ward/department. Out of 205, $118 \mathrm{HCW}$ s were enrolled in the study.

\section{Nasal swab collection}

Sterile cotton swabs were used for sample collection. The sample was obtained by rotating the swabs gently for five times on both nares of the study participants so that the tip is entirely at the nasal osteum level and it was transported to the laboratory using Stuart transport media.

\section{Culture and identification}

Swabs were inoculated on to Mannitol Salt Agar (MSA) (OXOID, UK) within one hour of collection and were incubated at $37^{\circ} \mathrm{C}$ for $24-48 \mathrm{hrs}$. After the plates were left at room temperature, coagulase test was performed using slide test method [7]. Those colonies that were mannitol fermenter (golden or cream colour on MSA) and tested coagulase positive were taken as $S$. aureus.

\section{Antimicrobial susceptibility testing}

Laboratory antimicrobial susceptibility testing was performed using modified Kirby- Bauer disc diffusion method which is recommended by the Clinical and Laboratory Standards Institute (CLSI) [7]. Colonies confirmed to be $S$. aureus were suspended in tryptone broth until matching with a standard turbidity $(0.5$ MacFarland). The suspension was used to inoculate a Mueller-Hinton agar (MHA) (OXIOD, UK). An oxacillin disk $(1 \mu \mathrm{g})$ (OXIOD, UK) was placed on the plates and the plates were incubated for 24 hours at $35^{\circ} \mathrm{C}$. Colonies with an inhibition zone of under $11 \mathrm{~mm}$ were read as "methicillin" resistant. In this study Staphylococcus aureus ATCC 25923 was used for the control [7].

\section{Statistical analysis}

The findings were statistically analyzed using descriptive statistics, Chi-square test $\left(\mathrm{X}^{2}\right)$ and $\mathrm{p}$-value $(\mathrm{p}<0.05$, statistical significant). The risk factor analysis of MRSA colonization was performed using SPSS (16 ${ }^{\text {th }}$ version) package.

\section{Ethical approval}

The study was approved by the institutional review board of Medical School of Addis Ababa University and all participants provided their written informed consent before participating in the study.

\section{Results}

Socio-demographic characteristics

A total of 118 health care workers were involved. The age ranged between 20 and 55 years (mean $=30.4 \pm 8.8$ ); $57(48.3 \%)$ were males and 61 (51.7\%) were females. The mean number of years in service was 6.1 \pm 8.5 .

\section{Rate of isolation}

Overall, $28.8 \%$ of the HCWs were S. aureus carriers (MSSA and MRSA), ranging from 20\% (pharmacists) to $37.5 \%$ (doctors). A total of 15 MRSA were isolated from 118 participants, giving an overall positivity rate of $12.7 \%$. Among the 57 males screened, 21 (36.8\%) and 10 (17.5\%) were positive for $S$. aureus and MRSA respectively, compared to $13(21.3 \%)$ and $5(8.2 \%)$ of the 61 females.

\section{Professional distribution of isolates}

The distribution of $S$ aureus and MRSA carriage across profession is presented in Table 1. MRSA carriage was particularly high among nurses (21.2\%), doctors (12.5\%) and technicians (12.5\%). Midwives, pharmacists and radiologists (together $17 \mathrm{HCWs}$ ) showed no MRSA carriage.

Based on their areas of work, the highest rate of $S$. aureus carriers (35.7\%) and MRSA carriers (57.1\%) were among HCWs in pediatrics and surgery, respectively (Table 2). Among the different specialties with patient contact, gynaecology and obstetrics had the lowest rate of MRSA carriage (Figure 1).

\section{Risk factors associated for MRSA colonization}

None of the risk factors assessed were significantly associated with the carriage rate of MRSA (Table 3). Highest positive rate was observed in the age group 20 to 29 years (5.9\%), followed by 30 to 39 years $(5.1 \%)$ and 40 to 49

Table 1 Distribution of S. aureus and MRSA carriage among the different professions

\begin{tabular}{llccc}
\hline $\begin{array}{l}\text { Profession/ } \\
\text { occupation }\end{array}$ & $\begin{array}{l}\text { No } \\
\text { sampled }\end{array}$ & $\begin{array}{c}\text { S. aureus } \\
(\mathbf{n}=\mathbf{3 4}) \\
\text { No }(\%)\end{array}$ & No (\%) & Total \% (n=118) \\
\cline { 4 - 5 } & & $3(37.5)$ & $1(12.5)$ & 0.85 \\
Doctors & 8 & $18(34.6)$ & $11(21.2)$ & 9.3 \\
Nurses & 52 & $2(22.2)$ & $0(0.0)$ & 0.0 \\
Midwives & 9 & $2(25.0)$ & $1(12.5)$ & 0.85 \\
Technicians & 8 & $8(24.2)$ & $2(6.1)$ & 1.7 \\
Purse Students & 33 & $1(20.0)$ & $0(0.0)$ & 0.0 \\
Radiologist & 3 & $0(0.0)$ & $0(0.0)$ & 0.0 \\
\hline
\end{tabular}


Table 2 Percentages of S. aureus (SA) and MRSA isolates in relationship with hospital's wards/departments

\begin{tabular}{lccc}
\hline $\begin{array}{l}\text { Ward/ } \\
\text { department }\end{array}$ & $\begin{array}{c}\text { No of samples } \\
(\mathbf{n = 1 1 8})\end{array}$ & $\begin{array}{c}\text { MRSA (\%) } \\
(\mathbf{n}=\mathbf{1 5})\end{array}$ & $\begin{array}{c}\text { SA (\%) } \\
(\mathbf{n}=\mathbf{3 4 )}\end{array}$ \\
\hline Medical & 18 & $2(50)$ & $4(22.2)$ \\
Surgical & 20 & $4(57.1)$ & $7(35.0)$ \\
Pediatrics & 14 & $2(40)$ & $5(35.7)$ \\
Gyn-Obs & 13 & $1(25)$ & $4(30.8)$ \\
Laboratory & 8 & $1(50)$ & $2(25.0)$ \\
OPD & 22 & $3(50)$ & $6(27.3)$ \\
Pharmacy & 5 & $0(0.0)$ & $1(20.0)$ \\
X-ray & 3 & $0(0.0)$ & $0(0.0)$ \\
ART clinic & 12 & $2(50)$ & $4(33.3)$ \\
Emergency & 3 & $0(0.0)$ & $1(33.3)$ \\
\hline
\end{tabular}

years $(1.7 \%)(\mathrm{p}>0.05)$. The MRSA prevalence rate for male HCWs $8.5 \%$ was twice time that of females HCWs (4.2\%), but not statistically different $(\mathrm{p}>0.05)$.

\section{Discussion}

In the present study, the nasal carriage of rate staphylococci varied among the different health professionals. The overall nasal carriage rate of $S$. aureus and MRSA was $28.8 \%$ and $12.7 \%$ respectively. The nasal carriage rate of $S$. aureus in the present study is lower than the study conducted in Gaborone hospital, Botswana (35.8\%) [4] and Valdivia Hospital, Chile (34.9\%) [8], and comparable to other studies conducted in Chile (27.5\%) [9]. In Nepal (25\%) [10] and $18.3 \%$ in Nairobi hospital, Kenya [3]. All differences between countries and hospitals may be explained by microbiological methods (from sampling technique to culture media), local infection control standards, and the local prevalence of MRSA.

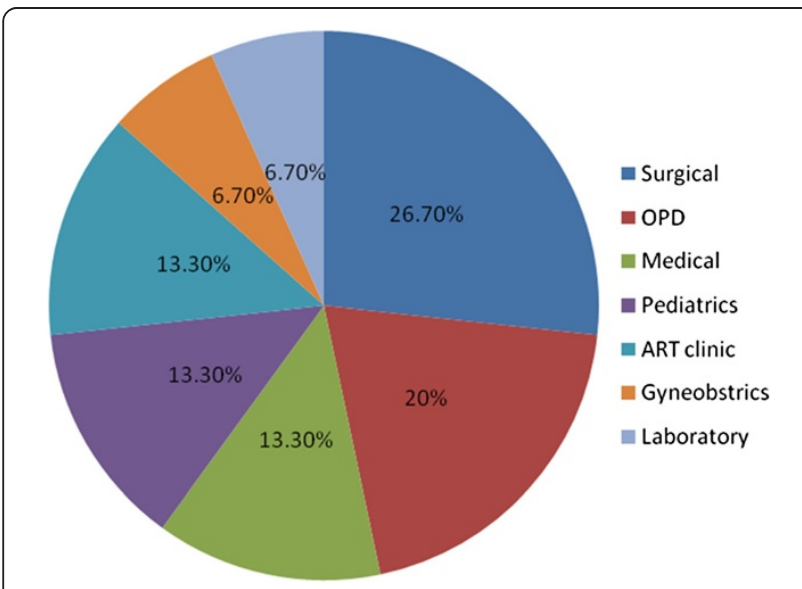

Figure 1 Percentage of MRSA isolates among the different wards/departments.
Table 3 Risk factors associated with MRSA colonization during the study period

\begin{tabular}{|c|c|c|c|}
\hline \multicolumn{2}{|l|}{ Associated factor } & $\begin{array}{c}\text { MRSA } \\
\text { carriers } \\
\text { No. (\%) } \\
\end{array}$ & $\begin{array}{c}\mathrm{p}- \\
\text { value }\end{array}$ \\
\hline \multirow{5}{*}{ Age group } & & & \\
\hline & $20-29$ & $7(5.9)$ & 0.13 \\
\hline & $30-39$ & $6(5.1)$ & \\
\hline & $40-49$ & $2(1.7)$ & \\
\hline & $50-59$ & $0(0)$ & \\
\hline \multirow[t]{2}{*}{ Sex } & Female & $5(4.2)$ & 0.128 \\
\hline & Male & $10(8.5)$ & \\
\hline \multirow[t]{10}{*}{ Ward/ department } & Medical & $2(1.7)$ & 0.960 \\
\hline & Surgical & $4(3.4)$ & \\
\hline & Pediatrics & $2(1.7)$ & \\
\hline & Gyn-Obs & $1(0.8)$ & \\
\hline & Laboratory & $1(0.8)$ & \\
\hline & OPD & $3(2.5)$ & \\
\hline & Pharmacy & $0(0)$ & \\
\hline & X-ray & $0(0)$ & \\
\hline & ART-clinic & $2(1.7)$ & \\
\hline & Emergency & $0(0)$ & \\
\hline \multirow[t]{7}{*}{ Profession/ occupation } & Doctors & $1(0.8)$ & 0.309 \\
\hline & Nurses & $11(9.3)$ & \\
\hline & Midwives & $0(0)$ & \\
\hline & Technicians & $1(0.8)$ & \\
\hline & Students & $2(1.7)$ & \\
\hline & Pharmacist & $0(0)$ & \\
\hline & Radiologist & $0(0)$ & \\
\hline \multirow{2}{*}{$\begin{array}{l}\text { No. of years in service or } \\
\text { practice }\end{array}$} & $\leq 5$ & $9(7.6)$ & 2.66 \\
\hline & $>5$ & $6(5.1)$ & \\
\hline \multirow[t]{3}{*}{ Hand washing habit } & Always & $4(3.4)$ & 0.184 \\
\hline & Sometimes & $11(9.3)$ & \\
\hline & Rarely & $0(0)$ & \\
\hline \multirow{3}{*}{$\begin{array}{l}\text { Habit of cleaning contaminated } \\
\text { surfaces/tables }\end{array}$} & Always & $6(5.1)$ & 0.079 \\
\hline & Sometimes & $9(7.6)$ & \\
\hline & Rarely & $0(0)$ & \\
\hline
\end{tabular}

From 34 Staphylococcus aureus isolates, 15 were oxacillin/ methicillin resistance with positivity rate of $44.1 \%$. This is far higher than $19 \%$ in Libyan hospitals [2], $11.38 \%$ in Tehran health care workers [11] and $5.5 \%$ in Ghaemshahr hospital personnel [12]. Among MRSA carriers, the highest rate was observed in the age group 20 to 29 years (5.9\%) compared with other age groups $(p>0.05)$. Moreover, the carrier rate was higher in health care workers $(7.6 \%)$ with $<5$ years service or practice experience $(\mathrm{p}>0.05)$. This higher prevalence among the younger and less practiced 
HCWs could be doe to their lack of knowledge with regard to infection control policies and their missing experience in taking care of these patients.

The MRSA carriage recorded in this study is higher than results obtained from surgical staff members or from environmental contamination of Tikur Anbessa Specialized Hospital in Ethiopia (27.6\%) [13]. Even lower rates 38.7\% and $40 \%$, were reported from Abidjan [14] and Nepal [10], respectively. A study conducted in Nigeria among health care workers indicated a higher rate $(52.5 \%)$, than the current study [15].

Obviously, all the above mentioned studies are not fully comparable, since the use of HCWs from specific specialties, and the differences in the study design such as sample size and method of MRSA identification might account for the disparity in the carriage rate. In additions, carrier rates might be influenced to poor personal hygiene of study participants, poor sanitation of the hospital and difference in sampling techniques.

In our study, males (17.5\%) were two-times more likely to be MRSA carriers than females. Only one other study has found a marginally higher prevalence of MRSA carriage in males, although it was not statistically significant [16]. Whether this is due to better commitment with infection control and hygienic practice of females, or other factors should be looked at in future studies.

MRSA carriage was particularly high among nurses (21.2\%), doctors (12.5\%) and laboratory technicians (12.5\%). In addition to the higher overall rate of MRSA carriage, the Nigerian study [17] showed a different distribution among the professions, with doctors and nurses being equally and highly colonized (65.2\% and 64.2\%), respectively. The higher MRSA rate among nurses and physicians could possibly be explained by the high frequency of patient contact among these professionals.

\section{Conclusions}

The present study indicates high nasal carriage rate of MRSA (44.1\%) among health care workers. The carriage rate was worse among nurses (21.2\%) than doctors (12.5\%). The highest rate of MRSA carriers were workers of surgical wards (57.1\%). The lowest rate of MRSA carriers was in gynecology and obstetrics (25\%).

In hospitals, HCWs nasal carriage of MRSA must be regularly screened and give an early warning of the presence of antimicrobial resistant pathogens. Measures be taken to control the spread of MRSA infection should include: laboratory based surveillance, isolation of colonized and infected patients, use of barrier precautions and basic infection control measures, and screening and treatment of MRSA-positive HCWs.

\section{Abbreviations}

MRSA: Methicillin-resistant Staphylococcus aureus; SA: Staphylococcus aureus; S. aureus: Staphylococcus aureus; HCWs: Health care workers.
Competing interests

The authors declare that they have no any competing interests.

\section{Authors' contributions}

AS designed the study, gathered and interpreted data, performed statistical analysis, and drafted the manuscript. TA and AM conceived the study, participated in coordination and interpretation of data, and helped to draft the manuscript. All authors read and approved the final manuscript.

\section{Authors' information}

We are doing research on infectious diseases including Staphylococcus.

\section{Acknowledgements}

We would like to thank Addis Ababa University, School of Graduate studies for giving fund. We also extend our grateful thanks to Dessie Regional Health Research Laboratory technologists for their cooperation, and for providing laboratory materials, provision of antibiotic discs and technical guidance for successful completion of this work.

\section{Author details}

${ }^{1}$ Department of Microbiology and Immunology, Faculty of Medicine, Wollo University, Dessie, Ethiopia. ${ }^{2}$ Department of Microbiology, Immunology and Parasitology, School of Medicine, Addis Ababa University, Addis Ababa, Ethiopia. ${ }^{3}$ Armauer Hansen Research Institute, Addis Ababa, Ethiopia.

Received: 19 August 2012 Accepted: 10 July 2013

Published: 2 October 2013

\section{References}

1. Aires-de-sousa M, Conceicao $\mathrm{T}$, de Lencastre $\mathrm{H}$ : Unusually high prevalence of nosocomial panton valentine leckociden-positive Staphylococcus aureus isolates in CapeVerde islands. J Clin Microbiol 2006, 44(10):3790-3793.

2. Ahmed MO, Elramalli AK, Amri SG, Abuzweda AR, Abouzeed YM: Isolation and screening of methicillin-resistant Staphylococcus aureus from health care workers in Libyan hospitals. East Mediterr Health J 2012, 18(1):37-42.

3. Omuse G, Kariuki S, Revathi G: Unexpected absence of meticillin-resistant Staphylococcus aureus nasal carriage by healthcare workers in a tertiary hospital in Kenya. J Hosp Infect 2012, 80(1):71-73.

4. Truong H, Shah SS, Ludmir J, Twananana EO, Bafana M, Wood SM, Moffat H, Steenhoff AP: Staphylococcus aureus skin and soft tissue infections at a tertiary hospital in Botswana. S Afr Med J 2011, 101(6):413-416.

5. Kumar P, Shukla I, Varshney S: Nasal screening of healthcare workers for nasal carriage of coagulase positive MRSA and prevalence of nasal colonization with Staphylococcus aureu. Biology and Medicine 2011, 3(2):182-186.

6. Kirecci E, Miraloglu M: A research of nasal methicillin resistant/ sensitive staphylococcus aureus and pharyngeal beta-hemolytic streptococcus carriage in Midwifery students in kahramanaras. Turkey Ethiop J Health Dev 2010, 24(1):57-60.

7. Cheesbrough M: District Laboratory Practice in Tropical Countries. Volume 2. 2nd edition New York: Cambridge University press; 2006.

8. Yazgi H, Ertek M, Ozbek A, Kadanali A: Nasal carriage of Staphylococcus aureus in hospital personnel and the normal population and antibiotic resistance of the isolates. Mikrobiyol Bul 2003, 37(2-3):137.

9. Tejero A, Gutierrez MA, Aiquel MJ, Brandago M, Gonzalez C, Broussain MT: Nasal carriage of Staphylococcus aureus among personnel working in a teaching hospital. Enferm Infec Microbiol Clin 1991, 9(6):351-353.

10. Shakya B, Shrestha S, Mitra T: Nasal carriage rate of methicillin resistant Staphylococcus aureus among at National Medical College Teaching Hospital, Birgunj. Nepal Nepal Med Coll J 2010, 12(1):26-29.

11. Mohammad Bagher K, Mohammad Kazem S-Y: Nasal Colonization rate of Staphylococcus aureus strains among Health Care Service Employee's of Teaching University Hospitals in Yazd. Acta Medica Iranica 2009, 47(4):315-317.

12. Ghasemian R, Najafi N, Shojaei Far A: Prevalence of Staphylococcus aureus carriages among Razi health care workers of Ghaemshahr, Iran. Mazandaran Uni Med J 2004, 44:79-85.

13. Tewodros W, Gedebou M: Staphylococcus aureus from a Surgical Department: Nasal carriage, environmental contamination, and susceptibilities to antimicrobials. Ethiop Med J 1983, 21:209-215. 
14. Akoua Koffi C, Dje K, Toure R: Nasal carriage of methicillin resistant Staphylococcus aureus among health care personnel in Abidjan (Cote d'Ivoire). Dakar Med 2004, 49:70-74.

15. Fadeyi A, Bolaji BO, Oyedepo OO: Methicilin Resistant Staphylococcus aureus Carriage amongst Healthcare Workers of the Critical Care Units in a Nigerian Hospital. Am J Infect Dis 2010, 6(1):18-23.

16. Anwar MS, Jaffrey G, Rehman Bhatti KU, Ayyib M, Bokhari SR: Staphylococcus aureus and MRSA nasal carriage in general population. J Coll Physicians Surg Pak 2004, 14:661-664.

17. Albrich WC, Harbarth S: Health care workers: source, vector or victim of MRSA. Lancet Infect Dis 2008, 8:289-301.

doi:10.1186/2047-2994-2-25

Cite this article as: Shibabaw et al: Nasal carriage rate of methicillin resistant Staphylococcus aureus among Dessie Referral Hospital Health Care Workers; Dessie, Northeast Ethiopia. Antimicrobial Resistance and Infection Control 2013 2:25.

\section{Submit your next manuscript to BioMed Central and take full advantage of:}

- Convenient online submission

- Thorough peer review

- No space constraints or color figure charges

- Immediate publication on acceptance

- Inclusion in PubMed, CAS, Scopus and Google Scholar

- Research which is freely available for redistribution 